\title{
Desain Komposisi Bahan Komposit yang Optimal Berbahan Baku Utama Limbah Ampas Serat Tebu (Baggase)
}

\author{
Mochammad Nuruddin, Rahmat Agus Santoso, Roziana Ainul Hidayati \\ Program Studi Teknik Industri, Program Studi Manajemen \\ Universitas Muhammadiyah Gresik \\ Jl. Sumatra 101 GKB Gresik (031)3951414 \\ Hp. 081330561307
}

\begin{abstract}
Abstrak - Bahan baku atau material komposit sebagai alternatif bahan baku non logam dipilih karena memiliki sifat ketahanan korosi yang lebih baik, karakteristik yang dapat dikontrol serta berat yang lebih ringan dan biaya produksi yang murah. Upaya yang dilakukan melalui inovasi desain bahan baku utama komposit yang memiliki keunggulan serta lebih aman dan ramah terhadap lingkungan. Salah satu jenis serat alam yang sangat potensial adalah ampas serat tebu (baggase). Ampas serat tebu merupakan limbah dari proses pengolahan gula yang pemanfaatannya kecil, diperkirakan sebanyak $40 \%$ dari ampas tebu tersebut belum dimanfaatkan secara optimal. Penelitian ini bertujuan untuk desain atau rancangan komposisi bahan baku atau material level optimal komposit dari limbah ampas serat tebu sebagai serat penguat utama material komposit dengan kombinasi alternatif bahan baku pendamping berupa serat batang/pelepah pisang dan serat/sabut kelapa sehingga dalam penelitian ini diistilahkan Tree in one of material komposit. Tahapan penelitian diawali dengan penerapan metode desain robust (Taguchi) dari indentifikasi variabel penelitian hingga pelaksanaan eksperimen dengan penentuan level faktor kualitas dan ortogonal array yang sesuai serta dengan replikasi 2 kali, Adapun hasil penelitian yang diperoleh adalah desain komposisi level optimal pada eksperimen ke-4 dimana komposisi bahan baku 70\%, 10\%, 20\% ( Matrik + Filler) dengan posisi struktur serat Searah, perekat yang sesuai memakai resin epoxy diperoleh rata-rata kekuatan bending sebesar 8,2404 MPa dan rata-rata kekuatan tarik sebesar 2,992748718 MPa, tentunya perlu dilakukan treatment spesifik untuk penelitian lanjutan yang lebih sempurna agar produksi komposit yang dihasilkan dapat ditingkatkan kualitasnya.
\end{abstract}

Kata Kunci : Ampas serat tebu, Komposit, desain komposisi optimal

\section{Pendahuluan}

Perkembangan kebutuhan bahan baku atau material komposit semakin meningkat di bidang industri seperti industri alat rumah tangga, industri otomotif, industri konstruksi, industri perkapakalan, industri penerbangan, industri militer dan industri lainnya. Bahan baku atau material komposit sebagai alternatif bahan baku non logam dipilih pada bidang industri-industri tersebut karena memiliki sifat ketahanan korosi yang lebih baik, karakteristik yang dapat dikontrol serta berat yang lebih ringan dan biaya produksi yang murah. Upaya yang dilakukan melalui inovasi desain atau rancangan bahan baku utama komposit yang memiliki keunggulan serta lebih aman dan ramah terhadap lingkungan.

Penelitian ini dilatarbelakangi pemanfaatkan limbah ampas serat tebu sebagai serat penguat utama material komposit dimana ampas serat tebu mengandung serat selulosa dan hemiselulosa yang cukup tinggi dialam dengan kombinasi alternatif bahan baku pendamping berupa serat batang/pelepah pisang dan serat kelapa yang mana serat-serat tersebut juga dianggap sebagai limbah sehingga dalam penelitian ini diistilahkan Tree in one of material komposit, hal ini menyempurnakan dari beberapa penelitian pendahulu yang mana hanya menggunakan 1 (satu) atau 2 (dua) saja bahan baku atau material serat pembuat komposit. Berdasarkan uraian di atas, maka perlunya dilakukan penelitian.

Tujuan penelitian ini untuk menghasilkan desain atau rancangan komposisi bahan baku atau material level optimal komposit dari limbah ampas serat tebu sebagai serat penguat utama material komposit dengan kombinasi alternatif bahan baku pendamping berupa serat batang/pelepah pisang dan serat/sabut kelapa yang mana serat-serat tersebut juga dianggap sebagai limbah, sekaligus sebagai upaya untuk mengurangi ketergantungan terhadap bahan baku logam melalui eksperimen laboratorium dalam rangka rancangan komposisi level optimal bahan baku utama dan bahan pendamping komposit. 


\section{Dasar Teori}

\section{Ampas Serat Tebu}

Tebu (Saccharum officinarum) adalah tumbuhan jenis rumput-rumputan yang tumbuh di daerah tropis yang dimanfaatkan sebagai bahan baku pembuatan gula. Dari proses pengolahan gula dihasilkan limbah padat yakni ampas serat tebu (bagasse) yang mengandung serat sebanyak 35$40 \%$ dari berat tebu. Ampas serat tebu (baggase) merupakan limbah organik yang dapat diolah lebih lanjut dan akan mempunyai nilai ekonomis yang tinggi,

Ampas serat tebu (baggase) mengandung selulosa dan hemiselulosa yang cukup tinggi, serat ini juga memiliki nilai ekonomis yang cukup tinggi selain merupakan hasil limbah pabrik gula tebu, serat ini juga mudah didapat, murah, tidak membahayakan kesehatan, dapat terdegredasi secara alami (biodegradability) sehingga nantinya dengan pemanfaatan sebagai serat penguat komposit mampu mengatasi permasalahan lingkungan.

\section{Pengertian Komposit}

Menurut definisi, komposit adalah struktur yang dibuat dari bahan-bahan yang berbeda-beda, ciri-cirinya pun tetap terbawa setelah komponen terbentuk sepenuhnya. Komposit adalah suatu material yang terbentuk dari kombinasi dua atau lebih material sehingga dihasilkan material komposit yang mempunyai sifat mekanik dan karakteristik yang berbeda dari material pembentuknya.

\section{Macam-macam bahan baku komposit}

Komposit pada umumnya terdiri dari 2 fasa:

\section{Matriks}

Matriks adalah fasa dalam komposit yang mempunyai bagian atau fraksi volume terbesar (dominan). Matriks mempunyai fungsi sebagai berikut :
a) Mentransfer tegangan ke serat.
b) Membentuk ikatan koheren, permukaan matrik/serat.
c) Melindungi serat.
d) Memisahkan serat.
e) Melepas ikatan.
f) Tetap stabil setelah proses manufaktur.

\section{Reinforcement atau Filler atau Fiber}

Salah satu bagian utama dari komposit adalah reinforcement (penguat) yang berfungsi sebagai penanggung beban utama pada komposit. Adanya dua penyusun komposit atau lebih menimbulkan beberapa daerah dan istilah penyebutannya; Matrik (penyusun dengan fraksi volume terbesar), Penguat (Penahan beban utama), Interphase (pelekat antar dua penyusun), interface (permukaan phase yang berbatasan dengan phase lain.
Secara strukturmikro material komposit tidak merubah material pembentuknya (dalam orde kristalin) tetapi secara keseluruhan material komposit berbeda dengan material pembentuknya karena terjadi ikatan antar permukaan antara matriks dan filler.

Syarat terbentuknya komposit: adanya ikatan permukaan antara matriks dan filler. Ikatan antar permukaan ini terjadi karena adanya gaya adhesi dan kohesi

Ada tiga faktor yang menentukan sifat-sifat dari material komposit, yaitu:

1. Material pembentuk. Sifat-sifat intrinsik material pembentuk memegang peranan yang sangat penting terhadap pengaruh sifat kompositnya.

2. Susunan struktural komponen. Dimana bentuk serta orientasi dan ukuran tiaptiap komponen penyusun struktur dan distribusinya merupakan faktor penting yang memberi kontribusi dalam penampilan komposit secara keseluruhan.

3. Interaksi antar komponen. Karena komposit merupakan campuran atau kombinasi komponen-komponen yang berbeda baik dalam hal bahannya maupun bentuknya, maka sifat kombinasi yang diperoleh pasti akan berbeda.

\section{Bahan Komposit Serat}

Bahan komposit serat terdiri dari serat yang terikat oleh matrik yang saling berhubungan. Bahan komposit serat ini terdiri dari dua macam, yaitu serat panjang (continous fiber) dan serat pendek (short fiber dan whisker). Penggunaan bahan komposit serat sangat efesien dalam menerima beban dan gaya. Karena itu bahan komposit serat sangat kuat dan kaku bila dibebani searah serat, sebaliknya sangat lemah bila dibebani dalam arah tegak lurus serat.

Continuous atau uni-directional, mempunyai serat panjang dan lurus, membentuk lamina diantara matriknya, jenis komposit ini paling sering digunakan. Tipe ini mempunyai kelemahan pada pemisahan antar lapisan, hal ini dikarenakan kekuatan antar lapisan dipengaruhi oleh matriknya.

Komposit serat dalam dunia industry mulai dikembangkan dari pada menggunakan bahan partikel. Bahan komposit serat mempunyai keunggulan yang utama yaitu strong (kuat), stiff (tangguh), dan lebih tahan terhadap panas pada saat didalam matrik (Schwartz, 1984).

\section{Kelebihan Bahan Komposit}

Bahan komposit mempunyai beberapa kelebihan berbanding dengan bahan konvensional seperti logam. Kelebihan tersebut pada umumnya dapat dilihat dari beberapa sudut yang penting seperti sifat-sifat mekanikal dan fisikal, keupayaan (reliability), kebolehprosesan dan biaya. 


\section{Kekurangan Bahan Komposit}

a. Tidak tahan terhadap beban shock (kejut) dan crash (tabrak) dibanding dengan metal.

b. Kurang elastis

c. Lebih sulit dibentuk secara plastis

Kegunaan Bahan Komposit

Penggunaan bahan komposit sangat luas, yaitu untuk :

a. Angkasa luar = Komponen kapal terbang, Komponen Helikopter, Komponen satelit.

b. Automobile $=$ Komponen mesin, Komponen kereta

c. Olah raga dan rekreasi $=$ Sepeda, Stick golf, Raket tenis, Sepatu olah raga

d. Industri Pertahanan = Komponen jet tempur, Peluru, Komponen kapal selam

e. Industri Pembinaan = Jembatan, Terowongan, Rumah, Tanks.

f. Kesehatan = Kaki palsu, Sambungan sendi pada pinggang

g. Marine $/$ Kelautan = Kapal layar, Kayak

\section{Metodologi Penelitian}

Penelitian terdiri dari 4 langkah tahapan sebagai berikut:
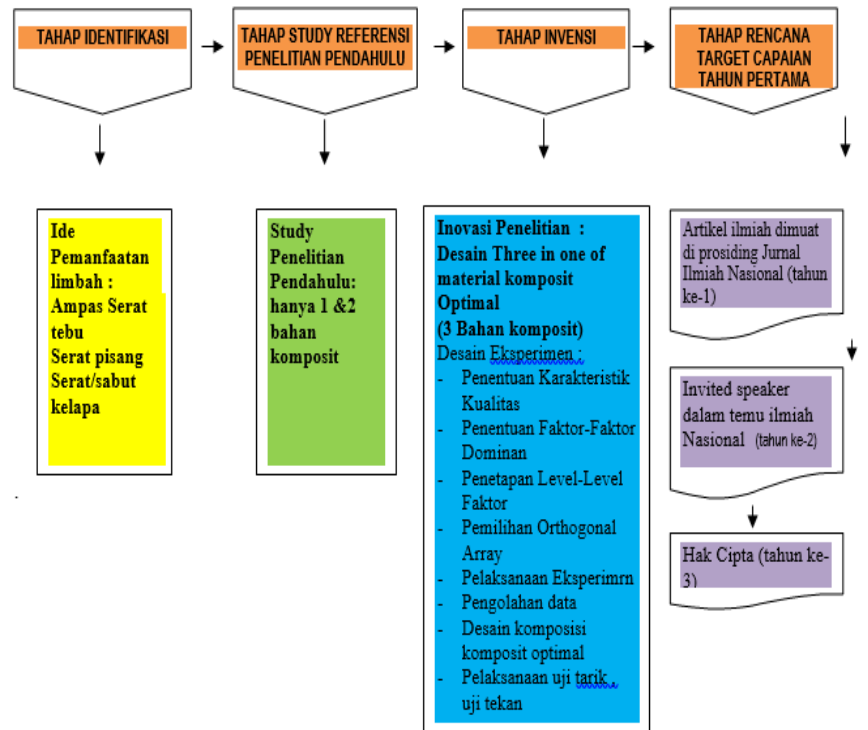

\section{Langkah-Langkah Penelitian}

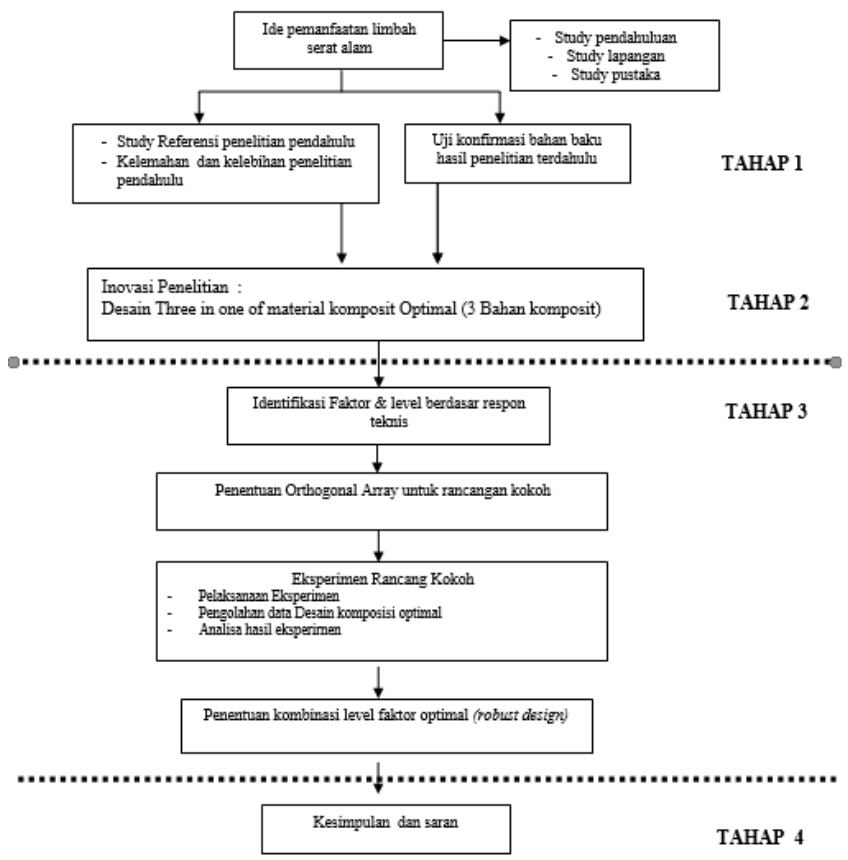

Gambar 1 Langkah-Langkah Penelitian

Proses pembuatan benda kerja bahan baku komposit

\section{A. Tahap Persiapan}

1. Serat alam direndam dalam air untuk membusukkan lignin selama satu hari

2. Perendaman dalam larutan $\mathrm{NaOH} 4 \%$ selama 4 jam

3. Pembilasan serat dan perendaman ulang untuk menetralkan $\mathrm{pH}$

4. Ekstraksi mekanik menggunakan mill atau alat bantu lain

B. Tahap Pelaksanaan Pembuatan bahan baku Komposit

1. Penyiapan cetakan

a. Untuk cetakan uji bending, dimensi cetakan adalah 15 × 6 x $0.5 \mathrm{~cm}$

b. Untuk cetakan uji tensile, dimensi cetakan adalah $18 \times 3 \times 0.5 \mathrm{~cm}$

\section{Penyiapan Matriks}

a. Matriks kanji/tapioka dicampur air dengan komposisi 50 : 50

b. Matriks PVAc dicampur air dengan komposisi 10:1

c. Matriks Epoxy dicampur Hardener dengan komposisi 1:1

\section{Perangkaian Komposit}

a. Pelapisan cetakan dengan aluminium foil

b. Pelapisan cetakan dengan wax

c. Meratakan matriks di permukaan cetakan

d. Penataan filler sesuai dengan kebutuhan

e. Meratakan matriks di atas filler 
f. Kompresi agar filler dan matriks memiliki antarmuka yang baik serta menghilangkan gelembung udara

g. Pemadatan

i. Matriks tapioka dan PVAc selama 3-4 hari dalam temperatur kamar

ii. Matriks epoxy selama 1 hari dalam temperatur kamar

iii. Selama 1 Jam dalam oven dengan temperatur $150^{\circ} \mathrm{C}$

h. Penyesuaian dimensi sesuai pengujian
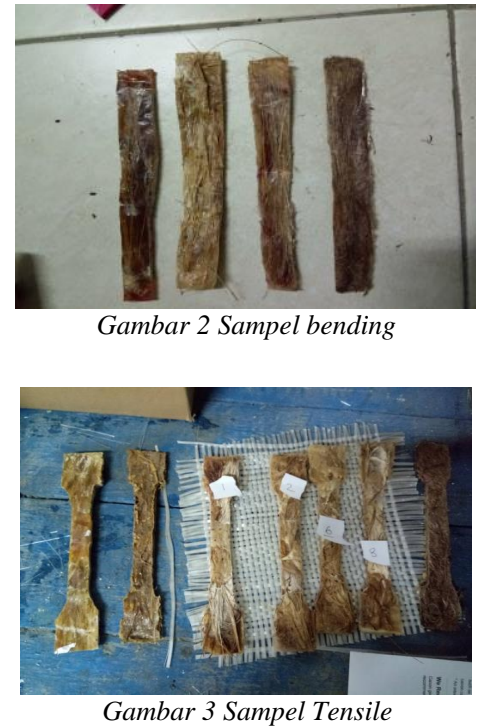

\section{Temuan dan Pembahasan}

\section{Tahap Identifikasi}

Tahap identifikasi adalah tahap awal yang didasari oleh terjadinya fenomena masalah pada obyek penelitian dengan merujuk pada referensi penelitianpenelitian pendahulu yang relevan sekaligus sebagai bentuk kreatifitas serta menginovasinya sehingga tercetuslah ide pemanfaatan limbah-limbah serat alami yang kurang termanfaatkan agar bernilai tambah ekonomis, sekaligus dapat menciptakan peluang baru dari bahan serat alami untuk bahan komposit yang dimasa yang akan datang merupakan bahan alternatif selain daripada logam.

\section{Tahap Study Referensi Penelitian Pendahulu}

Pada tahapan study referensi penelitian-penelitian pendahulu yang dilakukan adalah yakni :

1. Critical review terhadap penelitian-penelitian pendahulu.

2. Analisis dari penelitian terdahulu dan melihat apa kelemahan dan kelebihan hasil penelitian pendahulu.

\section{Tahap Invensi}

Tahap invensi adalah tahap inovasi penelitian dari pengembangan ide-ide pemanfaatan limbah serat alami yang kurang dimanfaatkan, didasari realita di lapangan bahwasannya serat-serat alami banyak terbuang dan tidak termanfaatkan serta dengan referensi penelitian penelitian pendahulu yang menjadikan ide untuk peneliti melakukan penelitian ini sekaligus pengembangan materi bahan baku komposit dari 1 (satu) atau 2 (dua) bahan baku komposit dalam penelitian sebelum-sebelumnya menjadikan 3 (tiga) bahan baku komposit dalam 1 (satu) komposisi .

\section{Pelaksanaan Eksperimen}

Untuk lebih merefleksikan kondisi sebenarnya, maka dalam melakukan eksperimen dilakukan pengulangan (replikasi). Pengulangan (replikasi) yang dilakukan dalam penelitian ini sebanyak 2 (dua) kali. Dari masingmasing komposisi bahan baku komposit dan uji-uji yang dilakukan.

Untuk pengujian parameter/karakteristik bahan baku komposit dengan alat ukur (instrumen) untuk uji Tarik , Uji bending/ tekan di lakukan di Laboratorium Inovasi Material, ITS Surabaya.

\section{Pelaksanaan Tahap Pengujian}

\section{Bending Test}

a. Menggunakan ASTM D790 dan peralatan bending lab teknik inovasi material, teknik material its

b. Meletakkan benda uji di dua titik penahanan

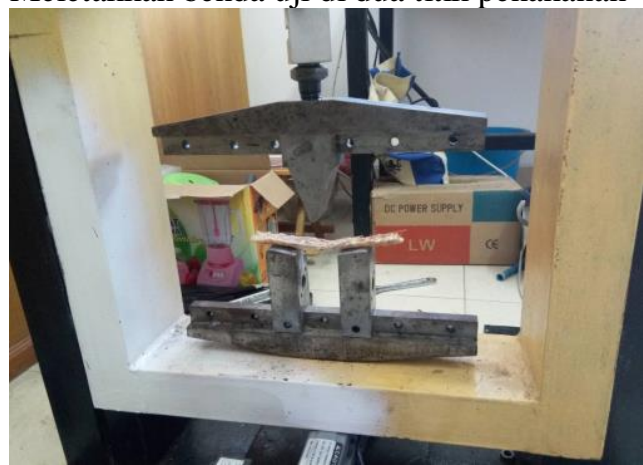

c. Menekan dengan indentor tepat di tengah-tengah sampai perubahan sudut $30^{\circ}$

d. Kembalikan seperti semula

e. Amati hasil

II. Tensile Test

a. Menggunakan ASTM D638 dan peralatan uji tensile lab teknik inovasi material, teknik material ITS

b. Meletakkan benda uji di dua titik penahanan

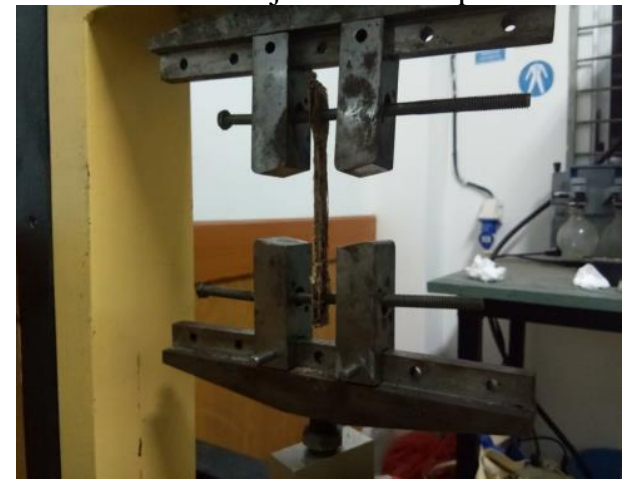


c. Menekan dengan indentor tepat di tengah-tengah sampai benda patah

d. Kembalikan seperti semula

e. Amati hasil

Adapun Rencana keseluruhan rancangan eksperimen komposisi bahan baku komposit dapat di lihat pada tabel dibawah .

\begin{tabular}{|c|c|c|c|c|}
\hline No. & Faktor & Level 1 & Level 2 & Level 3 \\
\hline 1. & $\begin{array}{l}\text { Jenis Bahan } \\
\text { Baku serat }\end{array}$ & $\begin{array}{l}\text { Serat } \\
\text { ampas } \\
\text { Tebu, } \\
\text { Serat } \\
\text { kelapa , } \\
\text { serat } \\
\text { pelepah } \\
\text { pisang }\end{array}$ & $\begin{array}{l}\text { Serat } \\
\text { ampas } \\
\text { Tebu, } \\
\text { Serat } \\
\text { kelapa , } \\
\text { serat } \\
\text { pelepah } \\
\text { pisang }\end{array}$ & $\begin{array}{l}\text { Serat ampas } \\
\text { Tebu, Serat } \\
\text { kelapa, serat } \\
\text { pelepah pisang }\end{array}$ \\
\hline 2. & $\begin{array}{l}\text { Bentuk } \\
\text { susunan } \\
\text { struktural } \\
\text { serat }\end{array}$ & Searah & Bersilang & Diagonal \\
\hline 3. & $\begin{array}{l}\text { Jenis Bahan } \\
\text { Perekat }\end{array}$ & $\begin{array}{l}\text { Lem } \\
\text { kanji }\end{array}$ & $\begin{array}{l}\text { Resin } \\
\text { epoxy }\end{array}$ & $\begin{array}{ll}\text { Lem } & \text { PVA } \\
\text { rajawali } & \end{array}$ \\
\hline 4. & $\begin{array}{l}\text { Ukuran } \\
\text { komposisi } \\
\text { bahan baku } \\
\text { komposit } \\
\text { Utama + } \\
\text { Pendamping) }\end{array}$ & $\begin{array}{l}50 \%, \\
30 \%, 20 \%\end{array}$ & $\begin{array}{l}60 \% \\
20 \% \\
; 20 \%\end{array}$ & $70 \%: 10 \% ; 20 \%$ \\
\hline
\end{tabular}

1.2. Gambar Sample Hasil Pengujian Bending Dan Tarik :
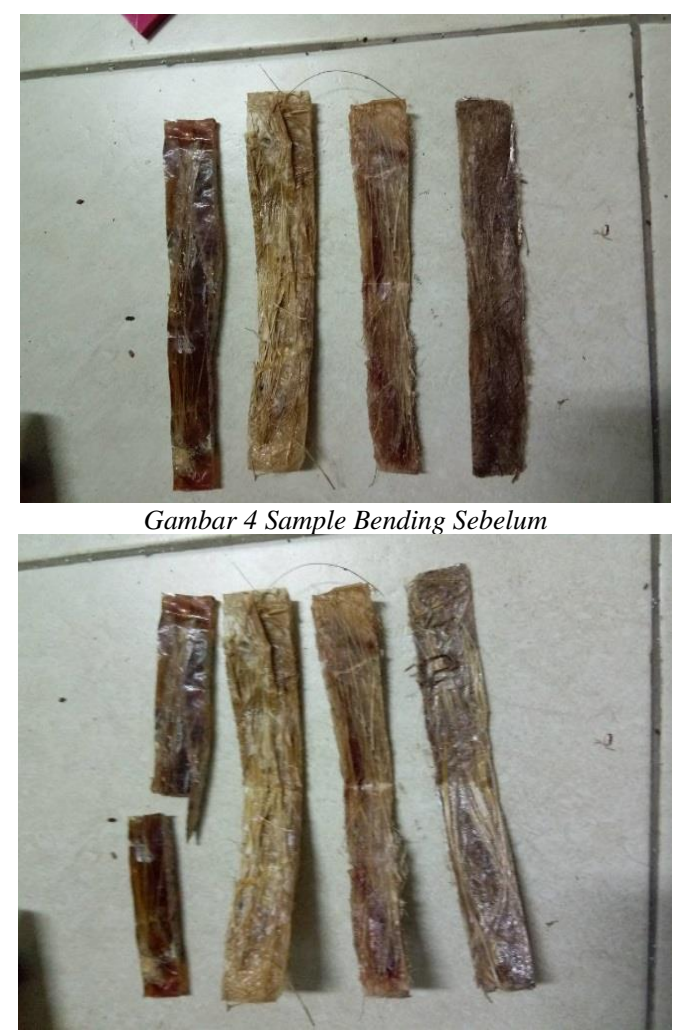

Gambar 5 Sample Bending Patah Setelah uji
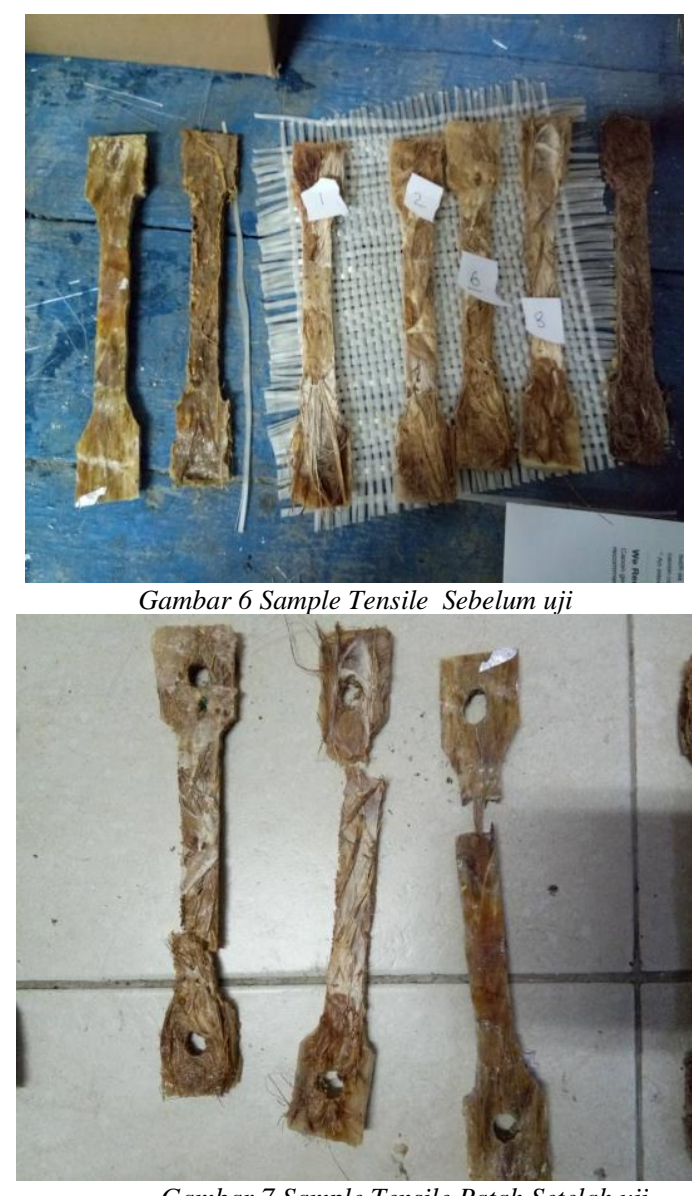

Gambar 7 Sample Tensile Patah Setelah uji

Untuk lebih ringkas hasil rancangan eksperimen selengkapnya dapat dilihat pada tabel dibawah ini .

Hasil Rancangan Eksperimen

\begin{tabular}{|c|c|c|c|c|c|c|}
\hline \multirow{2}{*}{ Eksperimen } & \multicolumn{4}{|c|}{ Faktor } & \multirow{2}{*}{$\begin{array}{l}\text { Rata-rata hasil } \\
\text { Uji } \\
\text { Bending/Tekan } \\
(\mathrm{MPa})\end{array}$} & \multirow{2}{*}{$\begin{array}{l}\text { Rata-rata } \\
\text { hasil } \\
\text { Uji Tarik } \\
(\mathrm{MPa})\end{array}$} \\
\hline & $\mathrm{A}$ & B & $\bar{C}$ & $\mathrm{D}$ & & \\
\hline 1 & 1 & 1 & 1 & 1 & 1,417 & 1,90968 \\
\hline 2 & 1 & 2 & 2 & 2 & 0,953539649 & 1,09436 \\
\hline 3 & 1 & 3 & 3 & 3 & 0,370092055 & 1,32298 \\
\hline 4 & 2 & 1 & 2 & 3 & 2,992748718 & 8,2404 \\
\hline 5 & 2 & 2 & 3 & 1 & 0,349849023 & 1,2317 \\
\hline 6 & 2 & 3 & 1 & 2 & 1,278477824 & 1,278477214 \\
\hline 7 & 3 & 1 & 3 & 2 & 0,7576693421 & 1,76144 \\
\hline 8 & 3 & 2 & 1 & 3 & 1,365492157 & 1,28075 \\
\hline 9 & 3 & 3 & 2 & 1 & 2,494071102 & 4,258266667 \\
\hline
\end{tabular}

\section{Analisa dan Interpretasi}

Dari hasil eksperimen uji bending dan uji tarik analisa yang dilakukan baik eksperimen awal dan replikasi/pengulangan 2 kali menunjukkan bahwa dari 9 eksperimen maka komposisi level faktor kondisi optimal di peroleh pada eksperimen ke- 4 yakni dengan rincian komposisi bahan baku komposit sebagai berikut : 


\begin{tabular}{|l|l|l|}
\hline No. & Faktor & komponen \\
\hline 1. & $\begin{array}{l}\text { Jenis Bahan Baku } \\
\text { serat }\end{array}$ & $\begin{array}{l}\text { Serat ampas Tebu, Serat kelapa, serat } \\
\text { pelepah pisang }\end{array}$ \\
\hline 2. & $\begin{array}{l}\text { Bentuk susunan } \\
\text { struktural serat }\end{array}$ & Searah \\
\hline 3. & Jenis Bahan Perekat & Resin epoxy \\
\hline 4. & $\begin{array}{l}\text { Ukuran komposisi } \\
\text { bahan baku } \\
\text { komposit ( Utama + } \\
\text { Pendamping) }\end{array}$ & \\
\hline
\end{tabular}

\section{Adapun rincian hasil Eksperimen ke- 4 dan 2} replikasinya :

\section{Untuk Uji Bending :}

\begin{tabular}{|l|l|l|l|l|l|}
\hline Urutan & $\begin{array}{l}\text { Load } \\
(\mathrm{kg})\end{array}$ & $\begin{array}{l}\text { Load } \\
(\mathrm{N})\end{array}$ & $\begin{array}{l}\text { Area } \\
(\mathrm{mm} 2)\end{array}$ & $\begin{array}{l}\text { Flexural } \\
\text { strength /Uji } \\
\text { Bending } \\
(\mathrm{MPa})\end{array}$ & $\begin{array}{l}\text { Rata-rata } \\
(\mathrm{MPa})\end{array}$ \\
\hline $\begin{array}{l}\text { Eksperimen } \\
\text { awal }\end{array}$ & 28,8 & 282,528 & 104 & 2,716615385 & \\
\hline Replikasi 1 & 29,4 & 288,414 & 97,5 & 2,958092308 & 2,992748718 \\
\hline Replikasi 2 & 39,4 & 386,514 & 117 & 3,303538462 & \\
\hline
\end{tabular}

\section{Untuk Uji Tarik :}

\begin{tabular}{|l|l|l|l|l|l|}
\hline Urutan & $\begin{array}{l}\text { Load } \\
(\mathrm{kg})\end{array}$ & Load (N) & $\begin{array}{l}\text { Area } \\
(\mathrm{mm} 2)\end{array}$ & $\begin{array}{l}\text { Tensile } \\
\text { strength /Uji } \\
\text { Tarik (MPa) }\end{array}$ & $\begin{array}{l}\text { Rata- } \\
\text { rata } \\
(\mathrm{MPa})\end{array}$ \\
\hline $\begin{array}{l}\text { Eksperime } \\
\text { n awal }\end{array}$ & 73,4 & 720,054 & 90 & 8,0006 & \\
\hline Replikasi 1 & 77,9 & 764,199 & 90 & 8,4911 & 8,2404 \\
\hline Replikasi 2 & 75,5 & 740,655 & 90 & 8,2295 & \\
\hline
\end{tabular}

Melihat hasil komposisi level faktor kondisi optimal di peroleh pada eksperimen ke- 4 menunjukkan bahwa ada kecenderungan kekuatan bending meningkat dari eksperimen awal diperoleh 2,716615385 MPa sampai dilakukan replikasi 2 kali diperoleh 3,303538462 MPa, demikian juga hal nya dengan kekuatan tarik yang juga kecenderungan meningkat dari eksperiemn awal diperoleh 8,0006 $\mathrm{MPa}$ sampai dilakukan replikasi 2 kali diperoleh 8,4911 $\mathrm{MPa}$, hal ini menggambarkan bahwa rancangan Tree in one of material komposit di kategorikan baik dan kondisi komposisi level faktor optimal bahan baku komposit 70\%:10\%;20\% dalam penelitian ini.

\section{Simpulan}

Dari pembahasan analisa tersebut diatas dapat diambil kesimpulan dari penelitian ini yaitu :

1. Desain komposisi bahan komposit yang optimal dari Tree in one of material komposit ( serat tebu, serat kelapa dan serat batang pisang) adalah 70\%:10\%;20\% , posisi strktur serat searah dengan perekat resin epoxy dengan diperoleh kekuatan bending rata-rata
2,992748718 MPa dan kekuatan tarik rata-rata 8,2404 MPa.

\section{Kepustakaan}

[1] Adi, G.T. (2006). Pengaruh Fraksi Volume Serat terhadap kekuatan Bening Komposit Kenaf Acak/polyester, Tugas Akhir Teknik Mesin Universitas Muhammadiyah Yogyakarta.

[2] Anonim (1998). Annual Book ASTM Standard,USA.

[3] Anonim. (2010, Nopember 11). Sifat-Sifat Komposit. Retrieved November 18, 2015, from Blogspot: http://decilix.blogspot.co.id/2010/11/sifat-fisika-dan-kimiabaja.html

[4] Nugroho, A. F. (2014, Februari 03). Komposit. Retrieved November 18, 2015, from Blogspot: http://forestmaknyus.blogspot.co.id/2014/02/sekilas-tentangbaja.html

[5] Santa, M. (2015, Juni 15). Makalah Kimia. Retrieved November 18, 2015, from Blogspot: http://mardhawaspj.blogspot.co.id/2015/06/makalah-kimiapadat.html? $\mathrm{m}=1$

[6] Gibson, R. F. (1994). Principle of Composite Material Mechanics. Desroit: McGraw-Hill, Inc. Mallick/Newmen (Eds). Composite Material Technology. New York : Hanser Publisher.

[7] Nayiroh, Nurul. 2013. Teknologi Material Komposit. Diakses tanggal 3 Desember 2015 pukul 11.34.http://nurun.lecturer.uinmalang.ac.id/wp content/uploads/sites/7/2013/03/MaterialKomposit.pdf

[8] Adi, G.T. (2006). Pengaruh Fraksi Volume Seratterhadap kekuatan Bening Komposit Kenaf Acak/polyester, Tugas Akhir Teknik Mesin Universitas Muhammadiyah Yogyakarta.

[9] Hariyanto, A. (2009). Pengaruh fraksi volume Komposit Serat Kenaf dan Serat Rayon Bermatrik Ploiester terhadap Kekuatan Tarik dan Impak, Fakultas Teknik Mesin Universitas Muhammadiyah Surakarta.

[10] Hartanto, L. (2009). Study Perlakukan Alkali dan Fraksi Volume Serat Terhadap Kekuatan Bending, Tarik, dan Impak Komposit Berpenguat Serat Rami-Polyester BQTN-157, Tugas Akhir, Universitas Muhammadiyah Surakarta,Surakarta

[11] Junaedi, F. (2008). Pengaruh fraksi volume terhadap kekuatan tarik dan bending komposit serat hybrid bambu dan serat Eglass/polyester, Tugas Akhir,

[12] http://www. Singapore Hingpolymer Chemical Products Pte Ltd / html_files/ datasheets/ SHCPs268.pdf pada tanggal 1 Maret 2011.

[13] Schwartz, M.M. (1984). Composite Material Handbook, Singapura: Mc Graw-Hill.

[14] Wahono, B. (2008). Pengaruh Perlakuan Alkali (NaOH) terhadap Karakteristik Komposit Serat Buah Kelapa Sawit/Poliester, Berita Teknologi Bahan dan Barang Teknik No.22/2008

[15] Wicaksono, A. (2006). Karakterisasi Kekuatan Bending Komposit Berpenguat Kombinasi Serat Kenaf Acak dan Anyam, Tugas Akhir Teknik Mesin Universitas Semarang. 